\title{
Identificação de funcionários com empresa pública no contexto de mudanças: o caso Finep*
}

\author{
Cláudio Barbosa da Rocha** \\ José Roberto Gomes da Silva***
}

\begin{abstract}
SuMÁRIO: 1. Introdução; 2. O processo de identificação; 3. Identificação com a organização e identidade organizacional; 4. Impacto das mudanças organizacionais na identificação; 5 . Contexto do estudo; 6 . Mudanças que afetaram os funcionários; 7. Metodologia; 8. Conclusões.
\end{abstract}

SUMMARY: 1 . Introduction; 2 . The identification process; 3 . Identification with the organization and organizational identity; 4 . The impact of organizational changes on identification; 5 . The study's context; 6 . Changes that affected the employees; 7. Method; 8. Conclusions.

Palavras-Chave: identidade organizacional; identificação; empresa pública; mudança organizacional.

KEY WORDS: organizational identity; identification; public organization; organizational change.

O quadro atual de mudanças nas empresas públicas tende a influenciar o processo de identificação de seus empregados com elas. Nesse cenário, incluem-se algumas instituições do segmento de ciência e tecnologia. Este artigo verifica os aspectos que influenciam o processo de identificação dos indivíduos com uma organização pública desse segmento em face das freqüentes mudanças de rumo e estrutura nela ocorridas. O objeto de análise é a Financiadora de Estudos e Projetos (Finep), empresa que atua no fomento de estudos, pesquisas, programas e projetos econômicos, sociais,

\footnotetext{
* Artigo recebido em jun. 2006 e aceito em mar. 2007.

** Mestre em administração de empresas pela PUC-Rio. Endereço: Praia do Flamengo, 200, 4ํㅗㅇ andar — Flamengo — CEP 22210-030, Rio de Janeiro, RJ, Brasil. E-mail: cbarbosa@finep.gov.br. $* * *$ Professor e pesquisador do IAG/PUC-Rio. Doutor em administração pela PUC-Rio. Endereço: Rua Marquês de São Vicente, 225 — Gávea - CEP 22453-900, Rio de Janeiro, RJ, Brasil. E-mail: jrgomes@iag.puc-rio.br.
} 
científicos e tecnológicos no país. Usando pesquisa documental e entrevistas com 24 funcionários, o artigo permitiu a composição de dois quadros conceituais sobre os aspectos que contribuem positiva (mapa da identificação) ou negativamente (mapa da frustração) para a relação dos indivíduos com a organização.

Employees' identification with a state-owned company in a changing context: the case of Finep

The recent changing scenario in public organizations tends to influence their employees' identification process. This is also the case of some science and technology institutions. This article identifies which aspects influence the identification of individuals with an S\&T public organization, considering its frequent changes of direction and structure. The object of analysis is the case of Finep, a public agency which finances economic, social, scientific, and technological studies, researches, projects, and programs in Brazil. Based on documental data collection and interviews with 24 employees, the study has permitted the composition of two conceptual frameworks corresponding, respectively, to the aspects contributing positively (identification map) as well as negatively (frustration map) to the relation between individuals and the organization.

\section{Introdução}

Nas últimas décadas, as empresas públicas brasileiras vêm sendo afetadas pelo quadro acelerado de mudanças políticas, sociais e econômicas no país. Entre outros aspectos, a situação macroeconômica ocasionou a redução da capacidade de investimento governamental em infra-estrutura e serviços, gerando descompassos na gestão dos recursos materiais e humanos dessas organizações, com reflexos em seu desempenho, em sua imagem diante da sociedade e na auto-estima de seus funcionários. O segmento de ciência e tecnologia foi, talvez, um dos mais afetados neste contexto. Egler (2001) exemplifica as mudanças nesse segmento, por meio do caso do Conselho Nacional de Desenvolvimento Científico e Tecnológico (CNPq), órgão que teve 10 presidentes em um período de 22 anos, ou seja, quase um a cada biênio.

No caso da Financiadora de Estudos e Projetos (Finep), foco deste estudo, mesmo sem se verificar tal alternância na direção, as diversas reestruturações ocorridas têm despertado questionamentos de seu corpo funcional, gerado indefinições de estratégia e ocasionado uma aparente crise na identidade da organização.

Trabalhos recentes na área de estudos organizacionais têm proposto tratar a questão da mudança organizacional sob enfoques ontológico e epistemo- 
lógico diferentes da visão gerencialista tradicional (Silva e Vergara, 2002). Giddens (1989), por sua vez, critica o tradicional dualismo entre os níveis macro e micro, nas análises sobre a realidade social, propondo um enfoque sobre o fluxo dinâmico da vida em sociedade, o qual compreende atividades e práticas que refletem instituições mais amplas, ao mesmo tempo em que as produzem. Sob essa ótica, as organizações devem ser entendidas como realidades dinâmicas que contribuem para formar a consciência dos indivíduos que as constituem.

O objetivo deste artigo é verificar os aspectos que influenciam o processo de identificação dos indivíduos com uma empresa pública, a Finep, em face das mudanças de rumo e estrutura que as organizações desse tipo vêm vivenciando no Brasil. Acredita-se, corroborando com Giddens, que esse processo de identificação também afeta os rumos das próprias mudanças organizacionais que o influenciam.

O artigo inicia com uma fundamentação teórica sobre o processo de identificação social e a dinâmica das identidades no contexto das mudanças organizacionais. Em seguida, apresentam-se a metodologia empregada, a descrição do contexto da empresa e a análise dos resultados obtidos no estudo, bem como as conclusões e considerações finais.

\section{O processo de identificação}

Na visão da teoria da identidade social (TIS), o autoconceito de um indivíduo é constituído, em parte, por uma identidade pessoal que abrange seus atributos idiossincráticos (exemplo, jeito de ser, preferências e habilidades) e, em parte, pelas identidades sociais decorrentes da sua autoclassificação nos grupos nos quais se considera inserido (exemplo, nacionalidade, sexo, raça, profissão, religião). Essa classificação possuiria duas funções básicas: possibilitar o ordenamento do ambiente social por meio de um processo de segmentação cognitiva, provendo o indivíduo de uma sistemática estruturada para a definição do outro; capacitar o indivíduo a se situar e se autodefinir diante da sociedade. A identificação social traria, então, respostas para a pergunta quem sou eu? (Ashforth e Mael, 1989).

Segundo Ashforth e Mael (1995), um dos motivos que levam o indivíduo a se identificar com determinadas categorias sociais é a busca pelo aumento da auto-estima, associando-se aos sucessos e ao status de um determinado grupo. Trata-se de um processo relacional e dependente do ambiente.

Johansson e Rasmussen (2001) vêem também uma perspectiva relacional na corrente teórica do construtivismo social. Um dos pressupostos dessa cor- 
rente é o de que os indivíduos baseiam a construção da sua realidade pessoal e subjetiva nas interpretações negociadas com os outros atores. Sob essa ótica, a identidade não pode ser vista como propriedade fixa ou estática: ela é negociada, aceita e rejeitada pelos atores que se auto-apresentam e reagem às apresentações alheias.

Além de relacional, a identificação é um processo comparativo (Tajfel e Turner, 1985) no qual o indivíduo busca construir uma imagem social. As diversas identidades são vistas de forma positiva pelo indivíduo quando reforçam atributos por ele apreciados, os quais são, por sua vez, influenciados pelas escalas de valor dos grupos dos quais faz parte.

Segundo Ashforth e Mael (1989), a noção de identificação possui forte natureza cognitiva, diferenciando-se de outros conceitos mais associáveis a comportamentos ou posicionamentos afetivos, tais como, respectivamente, a dedicação e a lealdade. Os mesmos autores fazem distinção entre os conceitos de identificação social e internalização. No primeiro, o indivíduo se referenciaria em termos de categorias sociais (eu sou), enquanto no segundo levaria em conta a incorporação de valores, atitudes e outros atributos de alta significação que constituem os seus princípios de vida (eu acredito). Essa distinção sugere que a aceitação de determinada classificação social para a formação do autoconceito não necessariamente implica a tácita concordância do indivíduo com todos os valores ou atitudes de um grupo.

Pratt (1998) associa o processo de identificação social a quatro tipos de motivações do indivíduo: segurança psicológica - a busca por resolver inconsistências emocionais; afiliação — a possibilidade de se perceber como membro de um grupo, a fim de vencer o isolamento social; autovalorização - a afirmação e construção de um autoconceito positivo; significado - a busca pela incorporação de valores que possam atribuir um propósito à vida.

Child e Rodrigues (2002) lembram, ainda, que o indivíduo tende a reforçar o seu senso de pertencimento a um grupo na medida em que percebe características compatíveis com sua identidade pessoal. Ainda, segundo eles, a interação com os demais membros do grupo realimentaria o seu compromisso de afiliação e a sua identificação.

\section{Identificação com a organização e identidade organizacional}

Albert e Whetten (1985) definem identificação com a organização como o nível de congruência entre a percepção que os membros possuem sobre a identidade da organização e as suas expectativas pessoais. Tal identificação se basearia em três características percebidas pelos indivíduos: a centralidade, relativa à 
real essência da organização; a singularidade, referente às características que fazem a organização única diante das demais; a continuidade, ou seu aspecto duradouro e consistente ao longo do tempo.

Autores como Hatch e Schultz (2000) vêem uma associação entre os conceitos de identidade e cultura organizacional. Os indivíduos tenderiam a se sentir atraídos por organizações com as quais compartilham valores (Albert e Whetten, 1985), o que, por meio da identificação, lhes forneceria uma base de significância e conectividade (Ashforth e Mael, 1989). Essa relação entre cultura e identidade é também observada por Machado-da-Silva e Nogueira (2001:37) para quem:

é possível entender que uma cultura estabelece uma identidade, uma marca reconhecível, quer pelos que dela participam, quer pelos que com ela interagem. Essa identidade corresponde a uma visão de mundo, a um modo particular de fazer as coisas, de interagir e de ser.

Whetten e Mackey (2002) diferenciam os conceitos de identidade na organização e identidade $d a$ organização. O primeiro se refere à noção de coletividade, suscitando questões a respeito de como os participantes vêem a organização, bem como de quais indivíduos exercem maior influência na interpretação da identidade organizacional. O conceito de identidade da organização, por sua vez, está relacionado à visão das organizações como atores sociais legítimos e engajados em participação ativa na sociedade.

Dutton, Dukerich e Harquail (1994) pressupõem que o indivíduo tende a se identificar com a organização na medida em que as imagens que desenvolve sobre ela contribuem para preservar seu autoconceito e elevar sua autoestima, além de proverem singularidade à organização. As autoras diferenciam tais imagens em dois tipos: a identidade organizacional percebida, englobando o que um indivíduo considera distintivo, central e duradouro a respeito da organização; a imagem organizacional externa percebida, refletindo o conceito que o indivíduo acredita que as pessoas externas mantêm sobre ela. Para essas autoras, a imagem que cada indivíduo mantém da organização pode ou não se alinhar à dos demais membros. Além disso, a imagem externa que cada membro constrói sobre a organização pode ou não ser idêntica à reputação a ela atribuída pelos não-membros.

Os atributos que conferem distinção à organização permanecem, muitas vezes, ocultos aos seus integrantes até que ela seja colocada sob ameaça (Albert e Whetten, 1985) ou que, por alguma circunstância, tenha sua atuação e desempenho mais seriamente questionados, como decorrência, por exemplo, de alterações de marcos regulatórios e movimentos de competidores. Do mesmo 
modo, inconsistências na ação da companhia podem fazer com que os participantes questionem essa identidade.

De acordo com Turner (1985), a identificação com uma coletividade pode surgir mesmo na ausência de coesão, similaridade, ou interação entre as pessoas, além de gerar impacto afetivo e comportamental. Na visão de Ashforth e Mael (1989), a identificação provê um mecanismo pelo qual um indivíduo pode continuar a acreditar na integridade da organização, apesar dos desmandos ou irregularidades de quem está na administração, ou permanecer fiel ao seu departamento, mesmo com a troca de pessoal.

Para Van Dyne e colaboradores (apud Dutton, Dukerich e Harquail, 1994), a identificação com a organização tende a potencializar nos funcionários o senso de cidadania organizacional, elevando seu nível de participação. Outros possíveis benefícios, no que diz respeito aos indivíduos, seriam o reforço da auto-estima, do sentimento de confiança e da preocupação com a sobrevivência da instituição (Ashforth e Mael, 1989, 2001).

Ashforth e Mael (1989) alertam, no entanto, para a necessidade de diferenciar os conceitos de identificação e de comprometimento. Uma pessoa pode apresentar alto comprometimento com uma organização mesmo sem possuir a percepção de compartilhar o seu destino com ela, mas porque ela se presta a seus objetivos pessoais de carreira. Se surgir outra organização que ofereça condições mais vantajosas, este indivíduo poderia se transferir para ela sem fortes impactos psicológicos.

Uma crítica apontada por Dutton, Dukerich e Harquail (1994) se refere ao fato de que o conceito de identificação com a organização costuma ser associado, em muitos estudos, apenas a aspectos positivos. Tais autoras observam, por exemplo, que se os integrantes do grupo interpretam a imagem externa da empresa como negativa, sua identificação com ela pode lhes gerar sentimentos como irritação, depressão ou estresse. Nesse caso, podem surgir situações de impacto indesejável, tais como o aumento da competição entre colegas ou a falta de motivação para tarefas de longo prazo. A manutenção desse quadro ao longo do tempo pode levar ao desprezo pelas normas tradicionalmente vigentes na empresa e, no limite, até mesmo à saída de pessoas. Ashforth e Mael (1989) lembram que, se levada a extremos, a identificação com a empresa também pode trazer conseqüências indesejáveis, como, por exemplo, quando gerentes profundamente identificados com a organização se tornam obcecados a ponto de ver com maus olhos funcionários que tenham fortes vínculos com alguma religião ou outra forma de afiliação.

Smidts, Pruyn e Riel (2003) observam que a adequação das informações sobre o contexto e o clima de comunicação na empresa afetam a disposição dos empregados a se identificarem com ela. Além de benéfico, um clima posi- 
tivo de comunicação pode fornecer informações sobre se um indivíduo é aceito como um colega de valor. Quando empregados recebem informações claras e suficientes sobre o que deles é esperado e sobre a importância de sua contribuição, elevam a sua compreensão quanto aos valores e normas da organização, bem como o sentido da sua vinculação a ela.

\section{Impacto das mudanças organizacionais na identificação}

Mudanças de estrutura, cultura, desempenho, fronteiras de atuação ou mesmo da estratégia da empresa podem fazer com que os funcionários reavaliem seus conceitos sobre a identidade organizacional, trazendo efeitos que podem ser positivos ou negativos para a corporação (Dutton, Dukerich e Harquail, 1994).

Por meio do estudo de casos em cinco diferentes organizações, nos quais utilizam a análise das narrativas de gerentes e empregados da base, Silva e Vergara (2002) identificam um quadro de referência sobre o conjunto de relações que influenciam a maneira como os indivíduos buscam reconstruir as suas identidades no contexto da mudança. O quadro sugere que, nesse processo de reconstrução das identidades, pesam: as relações internas à organização, tais como aquelas com superiores, subordinados e com os diferentes grupos identitários que se compõem no contexto da mudança; as relações extramuros, ou seja, as relações familiares, com antigos colegas e com os diferentes grupos exteriores à organização com os quais o indivíduo se identifica, bem como os papéis que ele reconhece para si, na vida em sociedade; a relação do indivíduo consigo mesmo, ou seja, o modo como ele define a sua identidade pessoal e busca se constituir como sujeito.

No Brasil, outros estudos como os realizados por Rodrigues (1997) e Carrieri (2001), acerca da privatização da Telemig, bem como por Machadoda-Silva e Nogueira (2001), comparativo entre as situações de mudança em duas empresas públicas, demonstram também os impactos das mudanças organizacionais sobre o processo de identificação dos indivíduos e sobre a identidade da organização.

Morrison e Robinson (1997) e Rousseau e Wade-Berzoni (1995) observam, ainda, que as mudanças que vêm ocorrendo nas relações de trabalho afetam o contrato psicológico dos indivíduos com a organização (Rousseau, 2001) e, como conseqüência, sua identificação e lealdade a ela. A gestão burocrática tradicional, apoiada em uma pretensa estabilidade no emprego em troca da dedicação e do desempenho, passou a dar lugar a um modelo no qual a empregabilidade não mais é assegurada e o trabalhador se torna o responsável por encontrar formas de atuação que agreguem valor à organização. Esse "novo 
acordo" tem sido visto como favorável aos trabalhadores mais jovens, de maior mobilidade e de custo mais baixo, em detrimento dos mais antigos, especialmente os mais estabilizados e especializados, provocando nesses últimos o sentimento de rompimento de seu contrato psicológico (Rousseau e WadeBerzoni, 1995) e afetando suas identidades (Silva e Vergara, 2002).

\section{Contexto do estudo}

A Finep é uma empresa vinculada ao Ministério da Ciência e Tecnologia (MCT), criada em 24 de julho de 1967 com o objetivo de fomentar estudos, pesquisas, programas e projetos econômicos, sociais, científicos e tecnológicos no país. Em termos da missão e da forma de captação de recursos, a história da empresa é marcada por períodos de avanços alternados com fases críticas, decorrentes das mudanças nas políticas do governo federal para o setor.

A Finep de hoje quer ser encarada como a agência federal de inovação. Tem papel fundamental na busca da liderança tecnológica, essencial para a garantia da competitividade das empresas no mundo globalizado. Por isso, analisa a estratégia de negócio das empresas e investiga sua vocação para a inovação, promove a integração destas com as universidades e cria condições financeiras diferenciadas para promover o investimento em tecnologia no país.

\section{Mudanças que afetaram os funcionários}

No início dos anos 1970, ocorreu considerável aumento do número de funcionários — de 25, em 1970, já havia 304 em 1975, quando a Finep passou pela primeira grande reestruturação, com auxílio de uma consultoria contratada.

Na década de 1980, o decreto da anistia trouxe para a empresa muitos dos antigos exilados políticos do meio científico. Em 1987 é lançado um novo plano de cargos e salários (PCS), vigente até hoje para uma parte dos funcionários. No mesmo ano é fundada a Associação dos Funcionários da Finep (Afin), representante dos interesses dos 700 funcionários à época.

Com a Constituição de 1988, o ingresso em qualquer empresa pública passava a ser feito obrigatoriamente por concurso público. A Finep, entretanto, só receberia novos empregados em 2001, ou seja, após 14 anos, quando ocorreu o primeiro dos dois únicos concursos até hoje realizados na empresa, em 2001 e 2002.

A Constituição de 1988 também determinava que o regime de trabalho das instituições bancárias deveria ser de turnos de revezamento de seis horas 
de expediente normal, salvo cargos de confiança. Isso deu margem a um número considerável de reclamações trabalhistas que solicitavam a implantação do regime de seis horas, com incorporação dos salários da época, bem como o pagamento de horas extras, nos casos de expediente de oito horas. Até a realização do estudo, tais processos permaneciam sem solução e haviam gerado passivo de valor ainda incerto.

À época do estudo, a empresa vinha passando por diversas mudanças, tais como: renovação de $1 / 3$ do quadro funcional, com implantação de um plano de demissão incentivada, em duas edições; definição de nova política operacional; alteração do plano de carreira, com coexistência do plano antigo e do novo; questionamentos jurídico-trabalhistas quanto ao enquadramento como instituição bancária; alterações da política industrial e de fomento à tecnologia do novo governo, implicando uma reestruturação da companhia. A direção da empresa apontava, ainda, a necessidade de se repensar a Finep e desenvolvia uma série de fóruns e atividades que visavam estimular a discussão entre todos os níveis operacionais e funcionais. Esse movimento vinha sendo acompanhado pelos funcionários com desconfiança, já que, no atual governo, havia ocorrido a primeira troca do titular do MCT.

\section{Metodologia}

Considerou-se este estudo exploratório (Gil, 2002), por buscar entender o processo de identificação dos funcionários com uma organização, em um contexto de mudanças. Quanto ao método de investigação, optou-se pelo estudo de caso em profundidade (Yin, 2002). Há também características de pesquisa participante, uma vez que um dos autores é funcionário da empresa desde 2002. A pesquisa foi autorizada e apoiada pelo Setor de Desenvolvimento e Administração de Recursos Humanos da Finep.

A coleta de dados, realizada de janeiro a maio de 2004, foi composta por pesquisa documental e entrevistas com funcionários da empresa. Foram acessados documentos diversos, entre os quais os sites da empresa na internet e todos os relatórios anuais da administração desde a criação. Para as entrevistas, utilizou-se um roteiro com questões semi-estruturadas, compreendendo tópicos referentes à visão e sentimentos dos indivíduos sobre a Finep, seu grau de identificação com ela, bem como os aspectos que contribuem para que desenvolvam tais percepções acerca da sua relação com a empresa.

Foram realizadas 24 entrevistas (5\% dos 536 funcionários à época) cuja duração variou de $45 \mathrm{~min}$ a $3 \mathrm{~h} 30 \mathrm{~min}$, resultando em 45 horas de gravação e mais de 400 páginas de transcrição. Os entrevistados que, por questões éticas, 
não são identificados nas análises, tinham entre 25 e 64 anos de idade, de dois a 29 anos de empresa, sendo oito mulheres e 16 homens, e exerciam diferentes funções, havendo representantes do quadro técnico (21) e do quadro de apoio (três), distribuídos em 14 departamentos, sendo 14 pessoas das áreas operacionais e 10 das áreas-meio, cobrindo, assim, um espectro significativo para a captação de possíveis diferenças nas visões sobre a empresa.

No tratamento dos dados das entrevistas utilizou-se análise de conteúdo do tipo classificado por Bardin (1979) como temática ou categorial, na vertente semântica, cujo enfoque se debruça sobre significados, em vez de inferências estatísticas. A análise foi efetuada com auxílio do software ATLAS.ti. Foram colhidos 1.848 trechos de narrativas, classificados em 111 códigos, de acordo com os conceitos abordados em seu conteúdo. Os códigos, por sua vez, foram agrupados em oito categorias ou famílias de conceitos, assim nomeadas: missão Finep, cultura, grupos, indivíduo, estrutura, empresa externa, empresa interna e política.

\section{Missão Finep}

Esta categoria representa itens de caráter normativo para o respondente, ou seja, seus valores, convicções acerca da noção de certo e errado e opiniões sobre a razão de existência da organização. Trata-se de um conceito associado ao que Dutton, Dukerich e Harquail (1994) nomeiam como identidade organizacional percebida e que, segundo tais autoras, contribui para que os indivíduos se sintam atraídos pela organização. Nesse sentido, a missão da Finep identificada no discurso dos funcionários, associada ao desenvolvimento do país, à transformação da sociedade e à melhoria da vida das pessoas, via ciência e tecnologia, demonstra ser fonte importante de identificação com a organização. Algumas falas sugerem, ainda, que a identificação com a missão é reforçada pelo fato de que ela enseja um sentimento altruísta que foge à lógica de competição normalmente associada às empresas privadas, a qual, por sua vez, é rejeitada em alguns discursos. Mesmo diante da pouca clareza sobre a atual missão formal da Finep, os entrevistados demonstram não ter dúvidas a respeito de qual seja ela e demonstram orgulho em compartilhá-la, conforme ilustrado neste depoimento: "Eu tenho orgulho. Eu sinto que aqui eu estou cumprindo um papel em prol da minha nação! E eu sou muito patriota".

Outro aspecto que demonstra reforçar a identificação com a missão da organização é o gosto pelo trabalho, a possibilidade de observar que a contribuição pessoal gera resultados concretos, como exemplifica um entrevistado: 
“(...) o primeiro projeto que eu analisei aqui está terminando agora. Redondinho, sabe? Tudo certinho (...). É uma coisa que faz parte do nosso trabalho que é muito legal: você ver que o seu trabalho teve resultados".

\section{Cultura Finep}

Cultura é uma categoria que expressa como os entrevistados percebem determinadas características da organização, tais como a forma de convivência entre as pessoas, bem como os valores e comportamentos coletivos mais observáveis, o que, segundo autores como Hatch e Shultz (2000), Ashforth e Mael (1989) e Machado-da-Silva e Nogueira (2001), tem relação com a identidade organizacional.

Talvez a característica mais marcante da cultura Finep se reflita na avaliação que os indivíduos fazem do ambiente de trabalho. O apreço entre colegas, de forma geral, é visto como um diferencial da empresa e serve como combustível para prosseguir e enfrentar as adversidades do dia-a-dia. Diversos relatos, tais como o apresentado a seguir, focalizam esta dimensão.

Eu acho que o ambiente aqui muito bom, por isso que eu te digo: é uma das coisas que eu mais gosto aqui na Finep (...). E às vezes você (...) está passando uma fase ruim da empresa, cheia de problemas institucionais, mas você gosta e diz: não, eu vou lá ver o fulano, eu vou lá ver o beltrano, cada um com a sua maluquice, com o seu comportamento.

Associado às características culturais que reforçam a identidade da organização, está o conceito de finepiano, termo utilizado para representar os funcionários da empresa, embora seja uma noção que pareça vir se modificando e que alguns, principalmente os mais novos, não a tenham clara. Algumas narrativas evidenciam que o conceito de finepiano costuma ser principalmente associado aos valores fundamentais da missão, tal como representado na fala a seguir, mas também é vinculado ao companheirismo das pessoas, ao idealismo e à busca de auto-realização, além da paixão pela empresa, apesar de todas as mudanças em curso.

Finepiano é uma pessoa que entende o que a Finep é, no sentido da missão da Finep, para que ela está por aqui, que veste a camisa da Finep, entendeu? Tem esse corporativismo, no sentido de querer que a empresa continue e que os funcionários estejam bem. 
Há, porém, características da cultura da empresa que parecem vir se modificando ou que representam condições não tão favoráveis à identificação de alguns indivíduos. Entre elas, citam-se a acomodação e a falta de comprometimento de alguns colegas, o que afeta o compartilhamento da identidade e gera problemas de relacionamento com eles.

\section{Grupos}

Grupos é a família de conceitos quanto às diferentes formas de categorização mútua entre funcionários, afetando suas identidades sociais na organização (Ashforth e Mael, 1989) e seu senso de pertencimento (Child e Rodrigues, 2002).

O primeiro par de grupos observado é o que diferencia as carreiras de acordo com a formação requerida. O grupo técnico de nível superior demanda formação universitária para os integrantes, enquanto o dito grupo de apoio contempla as funções auxiliares e operacionais, para as quais se exige nível médio de escolaridade. Com a Constituição Federal de 1988, os funcionários do grupo de apoio, mesmo com nível universitário, passaram a não mais poder migrar para a carreira de técnico de nível superior, a não ser por meio de concurso público, o que foi agravado pela falta de concursos para a empresa até 2000. Além disso, os concursos realizados em 2001 e 2002 foram somente para cargos de nível superior, passando o quadro de apoio a ser complementado por mão-de-obra terceirizada, o que gerou queixas entre os mais qualificados. Os relatos não indicam a existência de afastamento significativo entre esses grupos, apesar de alguns perceberem certa discriminação ao grupo de apoio e a maioria dos entrevistados ser de membros do grupo técnico.

Os concursos públicos trouxeram também um novo grupo para a Finep: os concursados, que foram batizados de "novos". A relação entre novos e antigos marca o principal tipo de divisão explícita no corpo funcional da empresa. As diferenças ainda são significativas, e eram mais acentuadas por ocasião da entrada da primeira turma de novos, em julho de 2001. A primeira diferença era a idade dos entrantes, cuja média era muito inferior à dos antigos, uma vez que havia mais de uma década sem renovação do quadro e jamais havia entrado contingente tão grande de funcionários na empresa (cerca de 60) em uma única ocasião. Se os novos eram vistos como jovens e superqualificados, os antigos passaram a ser considerados velhos e desatualizados. Isto desprezava a experiência profissional, forte nos antigos e não tão forte nos novos.

A maior mágoa dos antigos, entretanto, foi a forma como, na sua opinião, a administração da época tratou a questão, sobrevalorizando os novos, sob o pretexto de que eles não possuíam os "vícios" dos demais. Esse fato ocor- 
reu diante de um quadro de estagnação nos cargos desde 1989, ano de ocorrência do último reenquadramento funcional na empresa. Na percepção dos antigos, os novos, muitos dos quais sequer tinham ouvido falar da Finep antes de lá ingressarem, foram utilizados pela administração como instrumento deliberado de divisão e de quebra da unidade do corpo funcional. Na percepção dos novos, por outro lado, eles estavam desafiados a reerguer uma empresa pública decadente, desatualizada e que precisava reassumir seu lugar de destaque no cenário do desenvolvimento nacional.

Hoje, embora não totalmente apaziguado, o quadro é mais ameno. A entrada da segunda turma de novos, em abril de 2002, foi menos traumática. Entende-se que há bom entrosamento entre os dois grupos, mas percebem-se, ainda, diferenças na forma como ambos são valorizados pelo discurso da cúpula da empresa.

O terceiro par de grupos surgidos nas entrevistas refere-se à distinção entre funcionários das áreas operacionais e das áreas-meio. Entendem-se como áreas operacionais aquelas ligadas à especificidade técnica de cada projeto, tais como a área de indústrias e a área de universidades. As áreas-meio dizem respeito a serviços e demandas horizontais que permeiam toda a empresa, tais como a informática, o departamento jurídico ou o desenvolvimento de recursos humanos. Não se percebe divisão tácita do corpo funcional devido a essa distinção, mas registraram-se, nas entrevistas, experiências peculiares a cada um dos grupos. Os funcionários das áreas-meio se sentem, por exemplo, excluídos de algumas das principais discussões na empresa.

\section{Indivíduo}

Esta categoria representa fatores relacionados a sentimentos e opiniões manifestados pelos entrevistados, acerca de suas identidades, sua identificação com a organização e de como o fato de ser finepiano influencia seu autoconceito (Ashforth e Mael, 2001).

Um primeiro aspecto refere-se ao quanto a imagem externa percebida (Dutton, Dukerich e Harquail, 1994), associada à imagem do funcionalismo público, exerce influência sobre o sentimento de valorização do indivíduo diante da sociedade. Os entrevistados, ainda que, de fato, sejam empregados sob o regime da CLT, consideram-se, por vezes, vítimas da visão estigmatizada do funcionário público: o "marajá" que não trabalha e recebe o dinheiro dos impostos, ou a clássica versão do indivíduo que pendura o paletó na cadeira, sem aparecer para trabalhar. Apesar de incomodados com esse estigma, os 
indivíduos consideram que ele não reduz o seu reconhecimento da importância do próprio trabalho, nem o seu orgulho em pertencer à organização.

Questionados sobre os aspectos que levam um indivíduo a ser identificado com sua organização, os entrevistados ressaltaram fatores diversos, tais como: a existência de uma identidade de princípios, ainda que reconheçam que ela nem sempre ocorre de modo pleno; o fato de se sentir bem no ambiente da organização; a existência de uma missão e de objetivos que correspondam aos anseios pessoais e que dêem espaço para se possa agir com consciência e autonomia. Muitos dos discursos, tais como o apresentado a seguir, apontam para a consciência de que essa identificação é possível, ainda que a organização não seja perfeita ou que não atenda plenamente aos anseios individuais, pois, no final das contas, o que pesa é o sentido de pertencimento, o senso de afiliação que o indivíduo desenvolve ao longo de sua convivência com ela.

Ser identificado pra mim seria ter uma alta tolerância em relação às imperfeições daquilo com o que você se identifica. Então, é, por exemplo: eu me sinto identificado com a Finep hoje. Apesar dos problemas de processo, apesar das limitações, apesar das dificuldades, nada disso me impede de querer estar aqui dentro, de querer fazer parte desse projeto.

A maior coincidência de opiniões aponta como principais origens da identificação: a finalidade da empresa, de contribuir para o desenvolvimento do país; o apreço pelo tipo de trabalho realizado; os desafios que a empresa permite vivenciar; a identificação com as pessoas. Alguns discursos dão conta, no entanto, de que o fato de se identificar com a organização não tira do indivíduo a capacidade de olhar criticamente para os problemas existentes.

Apesar de, em sua maioria, se sentirem identificados com a Finep e demonstrarem orgulho pelo trabalho e pela empresa, alguns se sentem abalados pelas dificuldades do contexto atual. A luta contra o "apesar de tudo" muitas vezes cansa, e alguns entrevistados, mesmo gostando da empresa, não a indicariam a um amigo como um bom lugar para se trabalhar ("Se eu tivesse certeza de que ela fosse continuar da forma como está, eu não tenho a menor dúvida de que eu não convidaria").

Essa ambigüidade de sentimentos revela, ainda, a existência de fatores que hoje abalam a motivação dos indivíduos, tanto como decorrência do conjunto de mudanças nos últimos tempos, quanto pela falta de perspectivas na empresa ("Tem dias que não tem como ficar, mas o que me faz chegar todo dia e cumprir o horário de oito horas é a minha responsabilidade").

O que se pode apreender dos discursos de alguns entrevistados é, portanto, um sentimento de que as mudanças mais recentes trazem a idéia de um 
rompimento de seu contrato psicológico com a organização, gerando frustração, angústia e preocupação quanto ao futuro dessa relação. Por outro lado, em outros pontos das entrevistas, os mesmos indivíduos se dão conta de que esses rompimentos não são suficientes para destruir o orgulho de pertencer à instituição e o apego emocional que nutrem com relação a ela. Esse apego emocional tem desdobramentos positivos, como o sentimento de respaldo, a crença na revitalização da empresa, o orgulho pela missão e por ser finepiano, além da dedicação ao trabalho. A síntese desse sentimento pela Finep é representada por meio de uma imagem utilizada de modo recorrente pelos entrevistados, quando se referem a ela: a figura materna. Essa forma de representação da empresa não elimina nos indivíduos, entretanto, o seu senso crítico em perceber que a relação dessa "mãe" com seus filhos nem sempre tem sido justa para ambos os lados: “(...) a Finep é uma mãe, entendeu? A gente é que às vezes (...) não sabe aproveitar”; “(...) mas, por outro lado, uma mãe (...) é mais benevolente, não? É mais bondosa, é mais generosa”.

\section{Estrutura organizacional}

Esta concentra conceitos relativos às percepções sobre os efeitos que as mudanças na estrutura organizacional acarretam na empresa, e, por conseguinte, no processo de identificação de seus empregados. Conforme a definição proposta por Albert e Whetten (1985), a identidade organizacional diz respeito àquilo que é mais central, duradouro e distintivo a respeito da organização. As freqüentes mudanças da estrutura põem em risco um dos pilares que sustentam essa noção de continuidade.

Diante da instabilidade na estrutura, verifica-se um clima de incerteza e indefinição. Essa incerteza é sentida por toda a empresa e repercute também na sua imagem externa, diante da opinião pública e das comunidades específicas mais relacionadas à área de ciência e tecnologia, afetando duplamente a percepção dos funcionários, seja em termos da identidade organizacional percebida, seja no que se refere à imagem externa percebida (Dutton, Dukerich e Harquail, 1994). Relatos como o transcrito a seguir confirmam, no entanto, a impressão de que os funcionários, em sua maioria, não são contra mudanças, mas ficam preocupados com a quantidade, intensidade e forma como elas vêm sendo feitas mais recentemente.

Não que eu seja contra mudar a estrutura, mas tem que ser um negócio pra quê? Por quê? Pensado, né? Com um rumo, não do jeito que acontece, que é ao sabor da entrada de uma nova direção, troca tudo, muda tudo, aí o cara não sabe o que mudou, aí muda de novo (...) e você fica perdidão. 
A volatilidade da estrutura prejudica, ainda, o planejamento das carreiras. As indicações pessoais para a ocupação de cargos estratégicos provocam desvalorização do desempenho técnico/profissional dos funcionários, o que gera ressentimentos com a organização e sua política de $\mathrm{RH}$, pela falta de meritocracia.

A falta de meritocracia, por sua vez, resulta na percepção de outros problemas, entre os quais: o desequilíbrio das competências e da carga de trabalho entre departamentos, com departamentos ociosos convivendo com outros sobrecarregados; subutilização profissional do empregado.

A falta de meritocracia e seus desdobramentos, associados à falta de reconhecimento, seja via $\mathrm{RH}$ ou pela chefia imediata, implica a falta de perspectivas para o empregado, reduzindo sua motivação e compromisso com a instituição. Esses sentimentos são reforçados pelo fato de que o departamento de RH da empresa é visto, por vezes, como um órgão "passivo", "distante dos funcionários" e que não tem espaço para influenciar a construção de uma política de gestão que atenda aos anseios dos empregados ("é uma mera coisinha, um apêndice dentro da empresa, que é aquilo dali: curso e treinamento").

\section{Empresa}

Neste tópico, que analisa a influência das características da Finep no processo de identificação de seus empregados, utilizaram-se duas famílias de conceitos: empresa interna, que representa como o entrevistado vê o comportamento da empresa, representada por sua administração, história ou comportamento institucional, porém voltados para dentro da companhia; empresa externa, que contempla o olhar do indivíduo para a atuação da companhia em termos da imagem que ela constrói externamente.

$\mathrm{Na}$ ótica interna, observa-se um quadro de desorganização administrativa que faz com que a Finep perca, na visão dos funcionários, um pouco do seu caráter empresarial. A falta de rotinas definidas e de regras claras causa incômodo nos entrevistados, conforme ilustra este relato: "A gente não sabe o que a gente faz, a gente não sabe os instrumentos que a gente trabalha, a gente não sabe os controles que a gente tem que usar (...) A Finep tá sendo constantemente reconstruída".

Observa-se também certo saudosismo dos mais antigos, cuja memória tenta resgatar as circunstâncias nas quais, no seu entender, a Finep era mais profissional, atuante, respeitada, as condições de trabalho eram mais favoráveis e o ambiente mais fraterno. 
As freqüentes mudanças e as indefinições provocadas pela falta de regras e procedimentos fazem com que a identidade da Finep seja vista pelos funcionários como "mal resolvida" ou até "esquizofrênica". Para os entrevistados, estas inconsistências afetam, ainda, a imagem externa percebida (Dutton, Dukerich e Harquail, 1994) da organização, uma vez que impedem que ela cumpra a contento a sua missão institucional como instrumento de desenvolvimento do país. Os funcionários se mostram, por vezes, perdidos e desiludidos em meio a esse cenário: "A coisa virou uma bagunça tão grande, mudou tanto que a gente não sabe mais exatamente qual é a da Finep".

Essas indefinições tendem a acirrar, ainda, uma preocupação antiga quanto à continuidade da empresa, uma vez que se percebe que essa continuidade depende da capacidade de cumprir o seu papel na sociedade, mas também de questões políticas: "Que dizem, né, que a Finep um dia vai acabar, (...) que está ruim das pernas, (...) mas são 16 anos ouvindo isso. Então eu fico assim, poxa, será que no 17ํan ano vai acabar? (...) Então a gente fica naquela".

Sobre o conceito de imagem externa percebida abordado por Dutton, Dukerich e Harquail (1994), há uma particularidade, no caso da Finep: tratase de uma empresa que, no entender dos entrevistados, é praticamente desconhecida da população em geral, apesar dos quase 40 anos de existência. Assim, o referencial de imagem externa que o finepiano utiliza está mais ligado aos públicos com os quais a empresa se relaciona diretamente, ou seja, basicamente os seus clientes (universidades e empresas), ou com o governo, o qual se faz representar também por outras instituições do setor de ciência e tecnologia. Os entrevistados se ressentem da falta de um melhor trabalho de imagem institucional, pois, mesmo acreditando na singularidade da forma de atuação e do objeto de trabalho da Finep, seu não-reconhecimento externo afeta o autoconceito de seus empregados e reduz o caráter distintivo da empresa diante da sociedade.

Essa falta de trabalho direcionado ao público externo é agravada por uma comunicação interna deficiente, pois não se divulgam internamente os feitos e realizações externas da empresa nem as ações de cada área. Ou seja, não se sabe o que o colega faz, e nem que isso é bom e está gerando resultados lá fora.

Alguns entrevistados consideram que, diante desses problemas, a imagem da organização perante seus públicos mais diretos e a sociedade como um todo não tem sido a mais favorável: "as pessoas que conhecem a Finep acham que a Finep é desorganizada (...) devido à pouca nitidez dos processos”. 


\section{Política}

Esta categoria representa fatores de influência política sobre a empresa pública, e na Finep em particular, tanto em termos externos quanto pela atuação dos diferentes grupos políticos dentro da instituição. As maiores queixas referemse ao uso deliberado da estrutura organizacional como instrumento para atender interesses específicos.

Na opinião dos entrevistados, a influência das políticas interna e externa traz efeitos negativos para a percepção dos indivíduos sobre a sua relação com a organização, afetando seu contrato psicológico, uma vez que ela reduz as expectativas de reconhecimento pelo mérito profissional. Essa visão negativa é ainda reforçada pelo sentimento de que algumas mudanças na estrutura são utilizadas apenas como pretexto para que se possam criar oportunidades para pessoas "de confiança". Pesa, também, o fato de que, em algumas mudanças ocorridas, a empresa opta por contratar consultores externos, em lugar de criar oportunidades de atuação para seus próprios funcionários.

A convivência com essas questões políticas em uma instituição de natureza técnica como a Finep, apesar de não ser bem-vista pelos funcionários, é encarada como um preço a se pagar, pelo fato de se tratar de uma empresa pública, levando o empregado a uma atitude conformista em relação a essa "realidade", apesar de perceber os danos que ela traz para a instituição ("Eu acho ruim, mas isso não é só na Finep, é da esfera pública mesmo (...) o pior é não ter uma continuidade").

\section{Conclusões}

Este artigo verificou os fatores que influenciam o processo de identificação dos indivíduos com a organização, em face das freqüentes mudanças de rumo e estrutura nas empresas públicas no Brasil. A análise do caso da Finep permite a composição de dois quadros de referência que podem contribuir para o conhecimento do tema e auxiliar o desenvolvimento de futuras pesquisas que se proponham a observar os processos de mudanças no contexto das organizações públicas, bem como propiciar aos gestores de tais organizações a possibilidade de melhor lidarem com as dificuldades inerentes a esses processos. A figura 1, "mapa da identificação", aponta para aspectos que contribuem para que os empregados mantenham sua identificação com a organização, diante das características do contexto de mudanças. A figura 2, "mapa da frustração", apresenta aspectos que contribuem para frustrar os indivíduos em sua relação com a organização, dificultando sua identificação com ela. 
Quatro tipos de aspectos compõem o mapa da identificação: confluência ideológica com os princípios e valores que regem a atuação da empresa diante da sociedade; identificação com a missão da organização e com o trabalho que ela realiza; relação afetiva com a organização; ambiente de trabalho.

Figura 1

\section{Mapa da identificação}

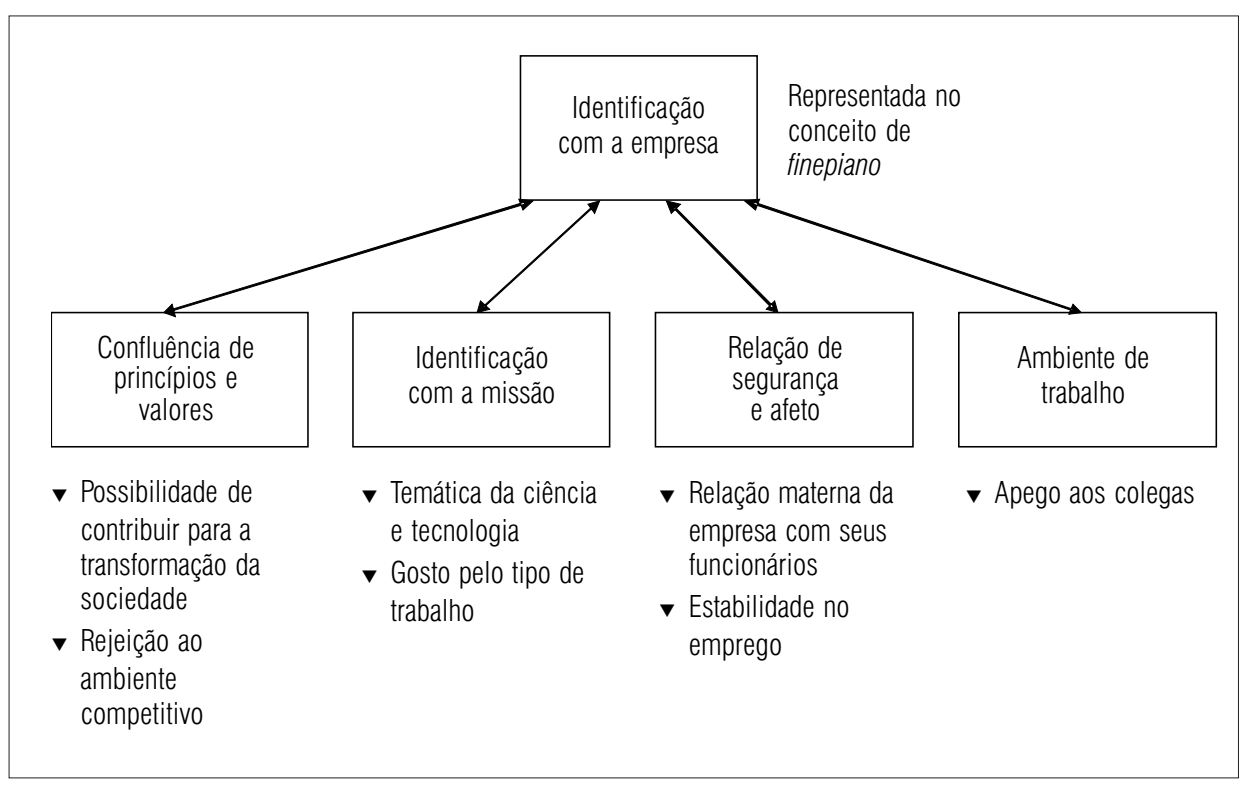

Os seguintes aspectos demonstram frustrar os indivíduos e afetar negativamente as possibilidades de se sentirem identificados com a organização: influências políticas; fraquezas na imagem externa; problemas relativos à estrutura da organização; deficiências na gestão de recursos humanos. Esses aspectos, bem como as características do caso Finep que os ilustram, são apresentados na figura 2 .

A Finep é um caso especial no contexto das empresas públicas no Brasil, dadas as especificidades de sua função institucional no cenário nacional de ciência, tecnologia e inovação. Apesar dos seus quase 40 anos, é, no entanto, praticamente desconhecida da população em geral. Este artigo também presta uma modesta contribuição para a reversão desse quadro. Futuros estudos poderiam buscar a validação ou complementação dos dois quadros, por meio da análise dos casos de outras empresas públicas. 
Figura 2

Mapa da frustração

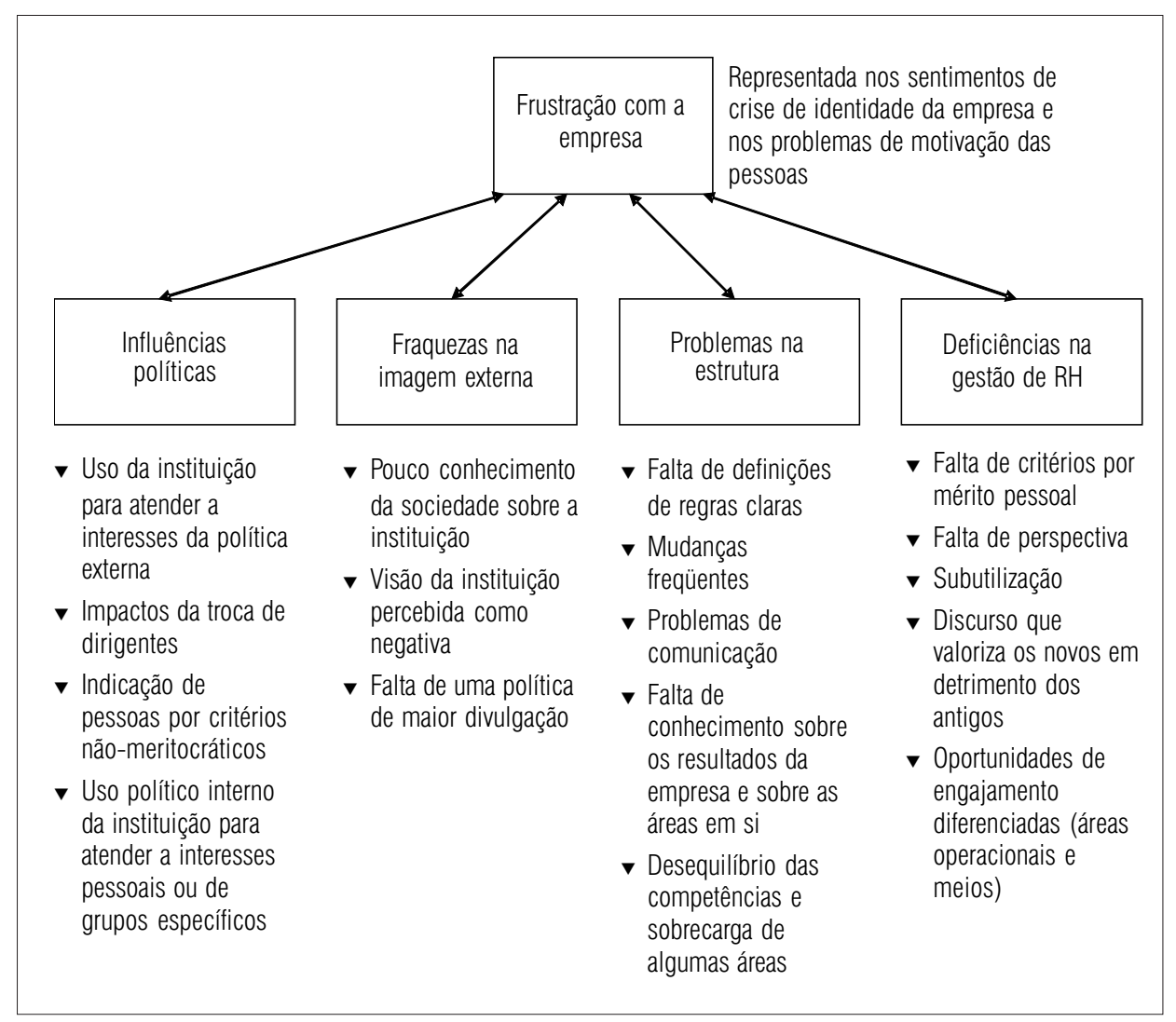

\section{Referências bibliográficas}

ALBERT, S.; WHETTEN, D. A. Organizational identity. In: CUMMINS, L. L.; STAW, B. M. (Orgs.). Research in organizational behavior. Greenwich: JAI Press, 1985. v. 7.

ASHFORTH, B. E.; MAEL, F. A. Social identity theory and the organization. Academy of Management Review, n. 14, 1989.

; __ L Loyal from day one: biodata, organizational identification and turnover among newcomers. Personal Psychology, n. 48, 1995.

; __. Identification in work, war, sports and religion: contrasting the benefits and risks. Journal for the Theory of Social Behavior, v. 2, n. 31, 2001. 
BARDIN, L. Análise de conteúdo. Lisboa: Edições 70, 1979.

CARRIERI, A. P. As metáforas de identidade de uma empresa pública antes e depois de sua privatização. In: ENCONTRO ANUAL DA ANPAD, 25. Anais... Campinas: Anpad, 2001.

CHILD, J.; RODRIGUES, S. Social identity and organizational learning. In: EASTERBYSMITH, M.; LILES, M. A. (Orgs.). Handbook of organizational learning. Oxford: Blackwell, 2002.

DUTTON, J. E.; DUKERICH, J. M.; HARQUAIL, C. V. Organizational images and member identification. Administrative Science Quarterly, n. 39, 1994.

EGLER, P. C. G. Porque ciência e tecnologia não são atividades estratégicas no Brasil. Revista Parcerias Estratégicas, n. 10, 2001.

GIDDENS, A. A constituição da sociedade. São Paulo: Martins Fontes, 1989.

GIL, A. C. Como elaborar projetos de pesquisas. 4. ed. São Paulo: Atlas, 2002.

HATCH, M. J.; SHULTZ, M. Scaling the Tower of Babel: relational differences between identity, image and culture in organizations. In: SHULTZ, M. et al. (Orgs.). The expressive organization: linking identity, reputation and the corporate brand. Oxford: Oxford University Press, 2000.

JOHANSSON, M.; RASMUSSEN, W. B. Constructing organizational identity: translating top management? In: NORDISKA FÖRETAGSEKONOMISKA ÄMNESKONFERENSEN. 16. Upsala: Finland, 2001.

MACHADO-DA-SILVA, C.; NOGUEIRA, E. E. S. Identidade organizacional: um caso de manutenção, outro de mudança. Revista de Administração Contemporânea, 2001. Edição especial.

MORRISON, E. W.; ROBINSON, S. L. When employees feel betrayed: a model of how psychological contract violation develops. Academy of Management Review, v. 22, n. 1, 1997.

PRATT, M. G. To be or not to be: central questions in organizational identification. In: WHETTEN, D. A.; GODFREY, P. C. (Orgs.). Identity in organizations: building theory through conversations. Thousand Oaks, CA: Sage, 1998.

RODRIGUES, S. B. R. Cultura corporativa e identidade: desinstitucionalização em uma empresa de telecomunicações brasileira. Revista de Administração Contemporânea, v. 1, n. 2, 1997.

ROUSSEAU, D. M.; WADE-BERZONI, K. A. Changing individual-organization attachments: a two way street. In: HOWARD, A. (Org.). The changing nature of work. San Francisco: Jossey-Bass, 1995. 
. Schema, promise and mutuality: the building blocks of the psychological contract. Journal of Occupational and Organizational Psychology, n. 74, 2001.

SILVA, J. R. G.; VERGARA, S. C. Mudança organizacional e as múltiplas relações que afetam a reconstrução das identidades dos indivíduos. In: ENCONTRO ANUAL DA ANPAD, 26. Anais... Salvador: Anpad, 2002.

SMIDTS, A.; PRUYN, A. T. H.; RIEL, C. B. M. The impact of employee communication and perceived external prestige on organizational identification. Academy of Management Journal, v. 39, n. 5, 2003.

TAJFEL, H.; TURNER, J. C. The social identity theory of intergroup behavior. In: WORCHEL, S.; AUSTIN, W. G. (Orgs.). Psychology of intergroup relations. 2. ed. Chicago: Nelson-Hall, 1985.

TURNER, J. C. Social categorization and the self-concept. A social cognitive theory of group behavior. In: LAWLER, E. J. (Org.). Advances in group processes. Greenwich, CT: JAI Press, 1985. v. 2.

WHETTEN, D. A.; MACKEY, A. A social actor conception of organizational identity and its implications for the study of organizational reputation. Business \& Society, v. 41, n. 4, 2002.

; FOREMAN, P. O. Member's identification with multiple-identity organizations. Organizational Science, v. 13, n. 6, 2002.

YIN, R. K. Estudo de caso — planejamento e métodos. Porto Alegre: Bookman, 2002. 